\title{
Performance and Ethanol Crossover of Passive Direct Ethanol Fuel Cell Stack
}

\author{
Panuwat Ekdharmasuit ${ }^{1 *}$ \\ ${ }^{1}$ Faculty of Science, Energy and Environment, King Mongkut's University of Technology North Bangkok, Rayong Campus, Rayong, \\ Thailand
}

\begin{abstract}
A dual-cell passive direct ethanol fuel cell (DEFC) stack with single ethanol tank was designed and tested to obtain the voltage requirement of electronics and to reduce weight and volume for practical applications. Ethanol crossover and cell performance were determined at different ethanol feed concentrations. Characterization techniques were used, including a cell polarization tests, a long-term steady voltage discharging measurement, and an electrochemical impedance spectroscopy (EIS). It was found that, before long-term steady voltage test, the optimum ethanol feed concentration was $2 \mathrm{M}$. The ethanol crossover increases with ethanol concentration increment over $2 \mathrm{M}$ and the ethanol crossover exhibited a negative effect on the open circuit voltage (OCV) and the cell performance. However, after a long-term steady voltage test, the best ethanol feed concentration was changed to $3 \mathrm{M}$. It was due to the difference of current density discharged during long-term operation. It can also be found that, after longterm steady voltage test, the cell resistance was apparently reduced. It may be explained that the mass transport of both liquid fuel and air as a reactant in the cell structure reached equilibrium during long-term operation.
\end{abstract}

\section{Introduction}

Fuel cell is the device converting the chemical energy of fuel directly into electrical energy. It is one of the attractive alternative power sources due to being environmental friendly and having absence of moving parts [1]. The direct liquid fuel cells (DLFCs) using liquid fuels as a fuel without a reformer is one of the most attractive power sources for portable devices. They are compact due to being able to operate at low temperature and can offer high energy density comparing to rechargeable batteries [2]. Among the investigated liquid fuels, methanol was the most used fuel in DLFCs in a few years ago. The performance of direct methanol fuel cells (DMFCs) was widely investigated and optimized [3]. Nevertheless, liquid methanol is toxic, easily volatile and inflammable. Recently, the replaceable fuel of methanol using in DLFCs is ethanol. It is less toxicity, natural availability, renewability and higher power density [4]. Then, direct ethanol fuel cells (DEFCs) have greater potential than DMFCs for commercial technology.

DEFCs usually operate with active system concept, which needs power for auxiliary part to feed fuel and oxidant to the cell. This system type is costly and suitable for large fuel cells. Another concept suited for small fuel cells is passive system, which serve the fuel and oxidant by natural forces, such as capillary, diffusion, convection and evaporation without external power sources [5]. Fuel cell operating by this concept can reduce cost and be used for portable devices.
In the active system, DEFCs still face with several problems. The most challenging one is that the DEFC performance suffers from ethanol crossover. The ethanol in the anode side normally cross through the electrolyte membrane to the cathode side by the external or natural force leading to fuel cell performance loss. Generally, researchers operate a fuel cell with diluted ethanol concentration to avoid the crossover of ethanol from the anode to the cathode. Although, delivering a diluted ethanol solution could alleviate the crossover, the polarization of the cell voltage may occur due to the insufficiency of ethanol at the anode electrode and also the system needs a large fuel reservoir capacity leading to an unacceptable for real portable power applications [6]. Beside this approach, to reduce the ethanol crossover, researches reported other solutions, such as modifying the electrolyte membrane [7], enhancing anode catalyst activity [8] and inserting the microporous layer at the anode structure [9-10]. Like the active system, the passive concept encounters with ethanol crossover leads to a performance loss. However, the crossover of ethanol in passive DEFC exhibits different features. As already mentioned, the permeation of ethanol from the anode to the cathode in passive DEFC is mainly affected by a natural force. Therefore, the suitable condition in passive DEFC operation might be different from active one.

Moreover, in practical, the portable electronic devices require input high-voltage of power sources. In order to obtain high-voltage output of DLFC, fuel cell stack can be achieved by connecting the single cells in series. Guo et al. [11]. demonstrated a prototype 1-W

\footnotetext{
* Corresponding author: panuwat.e@sciee.kmutnb.ac.th
} 
passive DMFC stack by connecting two single cells in series and studied different fuel feeding modes on cell performance. Wang et al. [12] proposed a 4-cell passive DMFC stack on a printed circuit board (PCP). Performances of the stacks with different numbers of single cells were performed and the dynamic performances of the cell stacks were investigated for portable applications. Masdar et al. [13] designed a 6cell passive DMFC stack with a large fuel reservoir. The effects of fuel concentrations and operation time were explained based on stability and degradation of cell performance.

Until now, a few studies on passive DEFC system operation has been reported. Pereira et al. [14] reported a performance optimization of passive DEFC. The effect of ethanol concentration and membrane electrode assembly (MEA) design parameters on the cell performance were investigated. Also, an analytical, steady-state and one-dimensional model was developed to describe and predict the ethanol, oxygen and water concentration profiles, temperature distribution, and ethanol crossover rate for passive DEFC [15].

In the above research works, the multi-cell passive DEFC stack has not been widely reported. There is one research which examined the dual-cell DEFC-based passive stack, but the experiment was conducted in alkaline condition [16]. Therefore, in this work, we fabricated and tested a passive system dual-cell DEFC stack in acid condition. The effect of ethanol crossover on cell performance was investigated with different ethanol concentrations varying from 1 to $3 \mathrm{M}$. The stability and degradation of stack performance were discussed by long-term cell operation. Electrochemical impedance spectroscopy (EIS) was performed to evaluate the cell resistance.

\section{Experimental}

\subsection{MEA preparation and stack fabrication}

A polymer electrolyte membrane used in the experiment was a Nafion ${ }^{\circledR} 115$ perfluorinated ion-exchange membrane (DuPont, Wilmington DE, USA). The membrane was boiled in $3 \% \mathrm{H}_{2} \mathrm{O}_{2}$ solution, $0.5 \mathrm{M} \mathrm{H}_{2} \mathrm{SO}_{4}$ solution, and deionized water, respectively. Each process was conducted at $70^{\circ} \mathrm{C}$ for $1 \mathrm{~h}$. A commercial gas diffusion electrode (GDE, E-TEK Somerset NJ, USA) utilizing a woven carbon cloth substrate and a $0.5 \mathrm{mg} \mathrm{Pt} \cdot \mathrm{cm}^{-2}$ on Vulcan $\mathrm{XC}-72$ carbon powder was used at the cathode. The inhouse anode catalyst layer was made, and its detail has been described in the publication elsewhere [10]. The inhouse anode catalyst layer was applied onto the gas diffusion layer (E-LAT ${ }^{\circledR}$; E-TEK, Somerset NJ, USA) using a painting technique and then was dried in an oven at $80^{\circ} \mathrm{C}$ for $1 \mathrm{~h}$. MEA fabrication was achieved by applying thin layers of anode and cathode electrode on each side of the treated Nafion membrane and pressing them together.

The dual-cell stack was fabricated by gathering two fuel reservoirs, two end plates, and two single cells, as presented in Fig. 1. The fuel reservoir having a volume of $10 \mathrm{~mL}$ was designed based on the acrylic material. Two pairs of current collectors were made of stainlesssteel plate with the thickness of $1.2 \mathrm{~mm}$. Two pairs of gaskets were made of silicon rubber to prevent leakage. Eight stainless steel nut-and-bolt pairs were used to clamp the stack.

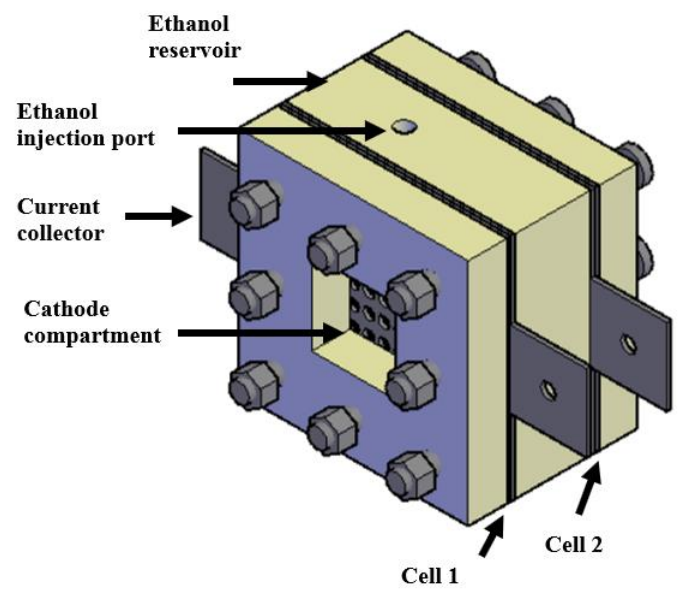

Fig. 1. Passive dual-cell DEFC stack.

\subsection{Cell characterization}

A cell pretreatment was carried out by $\mathrm{H}_{2} /$ Air activation process for $2 \mathrm{~h}$ and then Ethanol/Air activation for $1 \mathrm{~h}$ The activation detail was explained here. The hydrogen gases were fed to the anode side at $20 \mathrm{ml} \cdot \mathrm{min}^{-1}$, whereas the cathode side was opened to the natural air. Both sides were performed at room temperature and atmospheric pressure. After that, Ethanol/Air activation was conducted by storing a $1.0 \mathrm{M}$ ethanol aqueous solution to the anode reservoir for $1 \mathrm{~h}$ to ensure a steady-state cell operation.

Cell polarization was measured by a potentiodynamic polarization mode at a scan rate of $10 \mathrm{mV} \cdot \mathrm{s}^{-1}$. A steady voltage discharging in potentiostatic mode was conducted by applying the cell voltage and recording the cell current with time for $5 \mathrm{~h}$. The cell impedance spectra were recorded using Potentiostatic mode by impedance/gain-phase analyzer. The voltage was controlled at $1.0 \mathrm{~V}$ with the range of measured frequency setting from $5 \mathrm{kHz}$ to $0.1 \mathrm{~Hz}, 10$ points per decade. The amplitude of the sinusoidal voltage signal was $10 \%$ by the voltage discharged. All experiments were tested at the ethanol concentration in the range of 1-3 $\mathrm{M}$ using a Potentiostat/ Galvanostat apparatus (Metrohm Autolab, Utrecht, The Netherlands) and conducted at room temperature and atmospheric pressure.

\section{Results and discussions}

To understand the ethanol crossover of fuel cell, a higher concentration of ethanol was fed to explore the cell behavior. Fig. 2 showed polarization curves of the passive dual-cell DEFC at ethanol concentrations in the range of 1-3 M. It can be seen that the ethanol concentration affected cell performance. Feeding ethanol 
concentration of $2 \mathrm{M}$ produced highest cell performance. However, at high current density region, using ethanol concentration of $3 \mathrm{M}$ generated highest cell performance which is believed that high feed concentration could improve mass transfer resistance alleviating inadequate of ethanol at high current production.

The power density curves of the cell at various ethanol feed concentrations are also illustrated in Fig. 3. The results show that the maximum power density of the cell was improved by feeding a higher concentration. The lowest maximum power density was $0.804 \mathrm{~mW} \cdot \mathrm{cm}^{-2}$ at an ethanol concentration of $1 \mathrm{M}$. However, the highest maximum power density was $1.516 \mathrm{~mW} \cdot \mathrm{cm}^{-2}$ at an ethanol concentration of $2 \mathrm{M}$. Further increasing the ethanol concentration to above $2 \mathrm{M}$ yielded a lower maximum power density, about $1.321 \mathrm{~mW} \cdot \mathrm{cm}^{-2}$ at an ethanol concentration of $3 \mathrm{M}$.

It is obvious that an optimal ethanol concentration was at $2 \mathrm{M}$ for maximum cell performance. This result was consistent with the previous literature [5], which concluded that the effect of ethanol concentration on fuel cell performance have two different effects: a positive and a negative one. They explained that a high ethanol concentration improves ethanol oxidation reaction but increase ethanol crossover leading to a mixed potential at the cathode side, while a low ethanol concentration reduces ethanol crossover but results in water crossover rates relating to water flooding at the cathode.

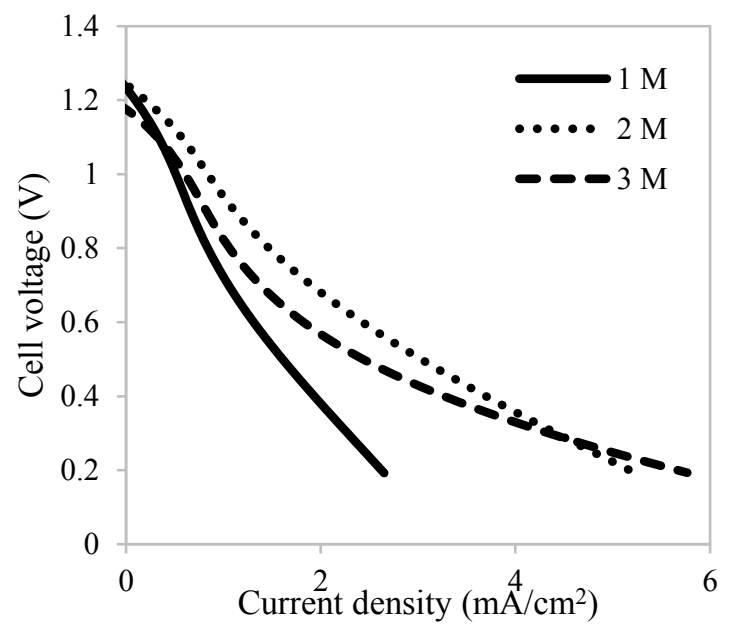

Fig. 2. Polarization curves of the passive dual-cell DEFC at different ethanol feed concentrations.

The in situ EIS of the cell was performed at different ethanol concentrations to investigate the cell ohmic loss including ionic and electronic resistance of the cell. A Nyquist plot at a controlled cell voltage of $1.0 \mathrm{~V}$ with various ethanol concentration was shown in Fig. 4. The EIS data were obtained by analyzing the values at the $\mathrm{x}$-axis intercept, which corresponded to the cell resistance. Based on that, the resistance of cell feeding ethanol concentration of $1 \mathrm{M}$ was highest at $1.512 \Omega$, whereas that of 2 and $3 \mathrm{M}$ were 1.126 and $1.229 \Omega$, respectively. It is suggested that using ethanol concentration of $2 \mathrm{M}$ showed lowest cell resistance due to a good management between ethanol crossover and water transportation through the membrane leading to highest cell performance.

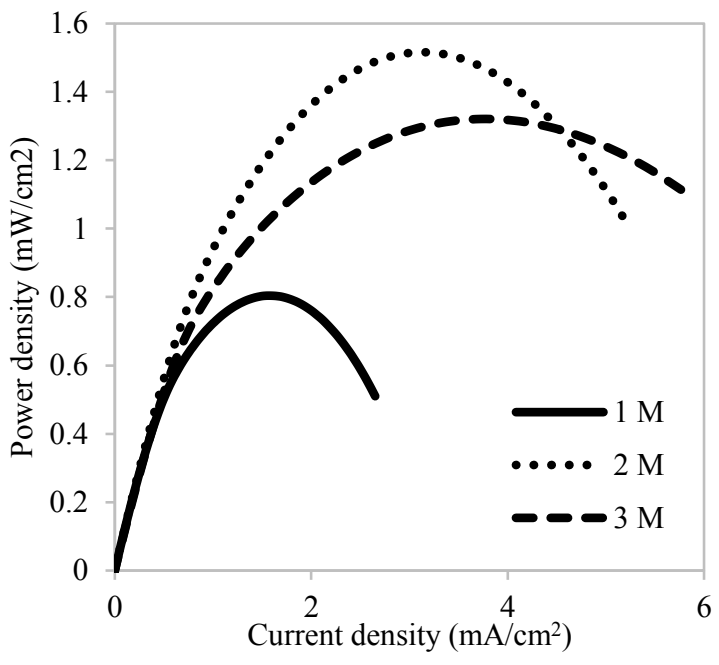

Fig. 3. Power curves of the passive dual-cell DEFC at different ethanol feed concentrations.

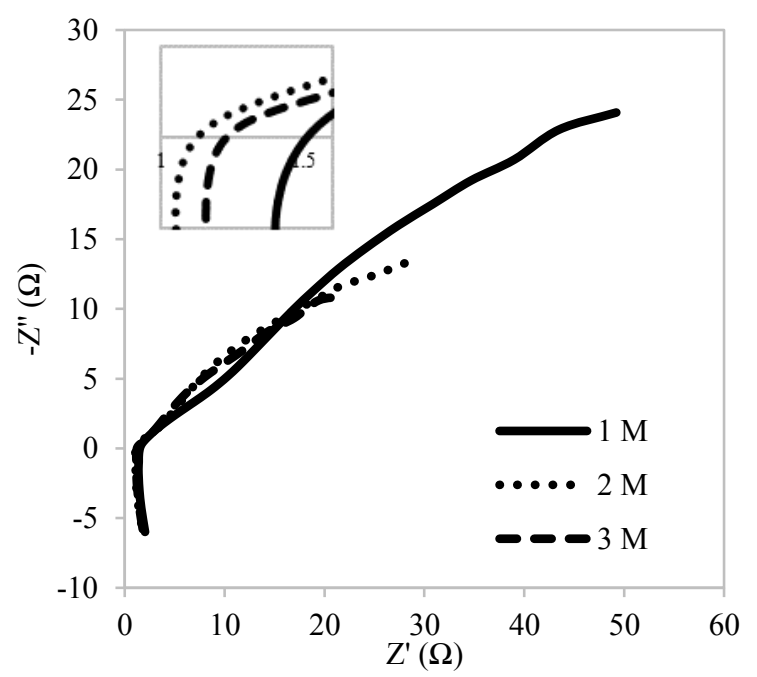

Fig. 4. Nyquist plot of the passive dual-cell DEFC operated at a cell voltage of $1.0 \mathrm{~V}$ and different ethanol concentrations.

To determine the passive dual-cell DEFC over a long period of time, a steady voltage discharging in potentiostatic mode was conducted under a constant voltage of $1 \mathrm{~V}$ for $5 \mathrm{~h}$, as shown in Fig. 5. It was obvious that the cell performance operated at low ethanol concentration of $1 \mathrm{M}$ was smallest for all the time, whereas, at the beginning of operation, cell using high ethanol concentration of $3 \mathrm{M}$ performed highest cell current density. Nevertheless, after around 8,000 second, the current operating with ethanol concentration of $2 \mathrm{M}$ became higher than that of $3 \mathrm{M}$. The last point of current density of cell using $2 \mathrm{M}$ was approximately $7.1 \%$ higher than that of $3 \mathrm{M}$. It was believed that the ethanol crossover affected the cell performance at high ethanol concentration especially testing for a long period of time. 
Consequently, after a steady voltage discharging measurement, the cell polarization was examined. Fig. 6 illustrated the cell polarization curves of the passive dual-cell DEFC at ethanol concentrations in the range of 1-3 $\mathrm{M}$ in a period after voltage discharge testing. Cell operated with ethanol concentration of $3 \mathrm{M}$ achieved highest cell performance, whereas that of $1 \mathrm{M}$ performed lowest cell performance.

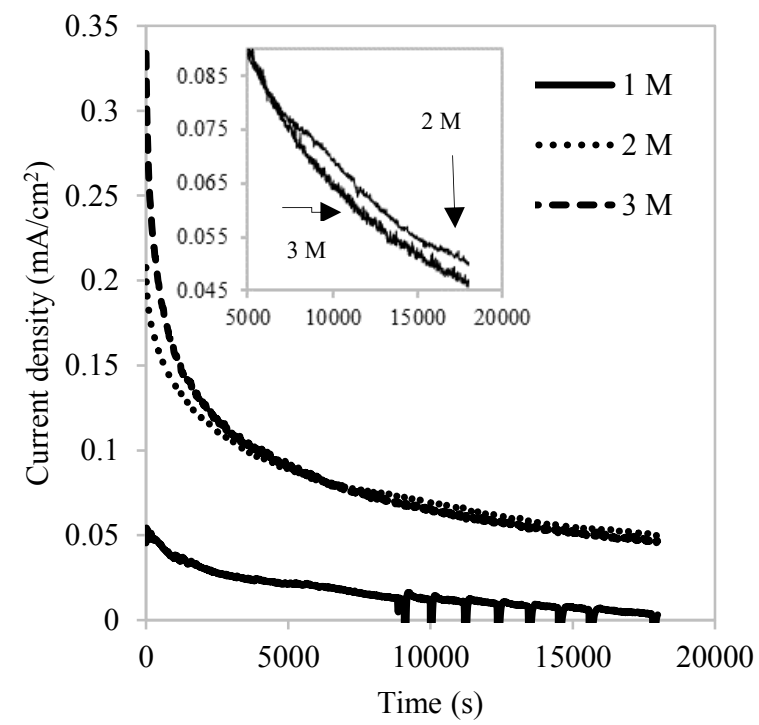

Fig. 5. Current density profiles with long operation time of the passive dual-cell DEFC operated at a cell voltage of $1.0 \mathrm{~V}$ and different ethanol concentrations.

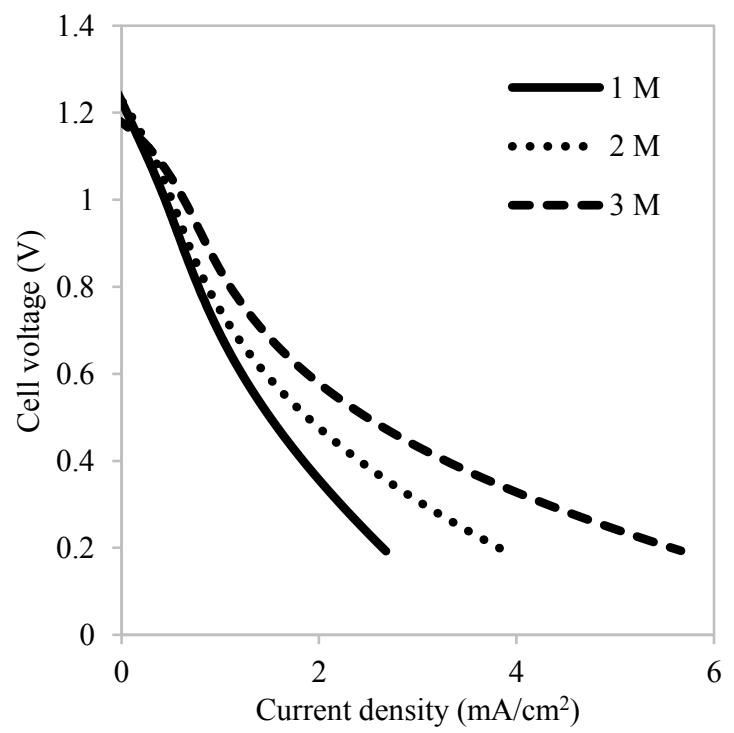

Fig. 6. Polarization curves of the passive dual-cell DEFC at different ethanol feed concentrations operated after a steady voltage discharging measurement.

The power density curves of the cell corresponding to the above polarization curves were illustrated in Fig. 7. The maximum power density was higher by feeding a higher ethanol concentration. The lowest maximum power density was $0.752 \mathrm{~mW} \cdot \mathrm{cm}^{-2}$ at an ethanol concentration of $1 \mathrm{M}$. The highest maximum power density was $1.319 \mathrm{~mW} \cdot \mathrm{cm}^{-2}$ at an ethanol concentration of $3 \mathrm{M}$. It was seen that this incident was different from the period before a steady voltage discharging measurement. A summary of maximum power densities at different ethanol concentrations and periods were shown in Fig. 8. The maximum power density of cell operated with $2 \mathrm{M}$ ethanol concentration decreased $36.4 \%$ to $0.964 \mathrm{~mW} \cdot \mathrm{cm}^{-2}$ and was lower than that of $3 \mathrm{M}$. The results can be explained by the evidence of the current density after 8,000 second. The cell operated with ethanol concentration of $2 \mathrm{M}$ produced current density higher than that of $3 \mathrm{M}$ approximately $7 \%$ for a long time period. It may be mainly attributed to the immediate species poisoning at the anode active layer leading to a lower cell performance [9].

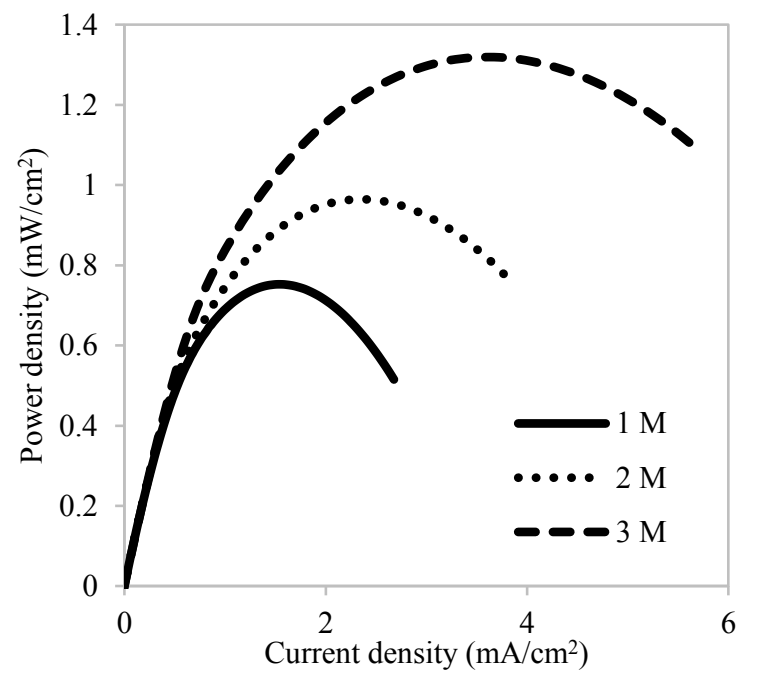

Fig. 7. Power curves of the passive dual-cell DEFC at different ethanol feed concentrations operated after a steady voltage discharging measurement.

The in situ EIS of the cell was performed at different ethanol concentrations to investigate the cell ohmic loss after a steady voltage discharging measurement. A Nyquist plot at a controlled cell voltage of $1.0 \mathrm{~V}$ with various ethanol concentration after a steady voltage discharging measurement was shown in Fig. 9. As previous mention, the EIS data were obtained by analyzing the values at the $\mathrm{x}$-axis intercept. Based on that, cell resistance $\left(\mathrm{R}_{\text {Cell }}\right)$ at different ethanol concentrations and periods were analyzed and illustrated in Fig. 10. After a steady voltage discharging measurement, the cell resistance with ethanol concentration of $1 \mathrm{M}$ was highest at $1.035 \Omega$, whereas that of 2 and $3 \mathrm{M}$ were 1.113 and $1.034 \Omega$, respectively. It was obvious that, after a steady voltage discharging measurement, the cell resistance of cell operated with ethanol concentration of $2 \mathrm{M}$ was the same comparing to that before one. However, the others evidently decreased. It could be explained that the mass transfer of fuel and reactant entirely reaches to equilibrium in both chemical and physical phenomenon $[9,10]$. 


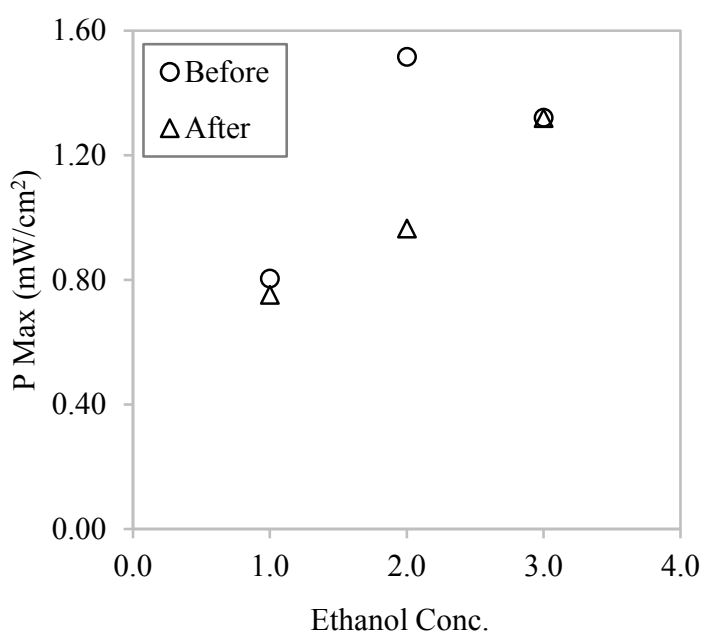

Fig. 8. Effect of ethanol concentration on the maximum power density $(\mathrm{P} \max )$ at different periods: before and after a steady voltage discharging measurement.

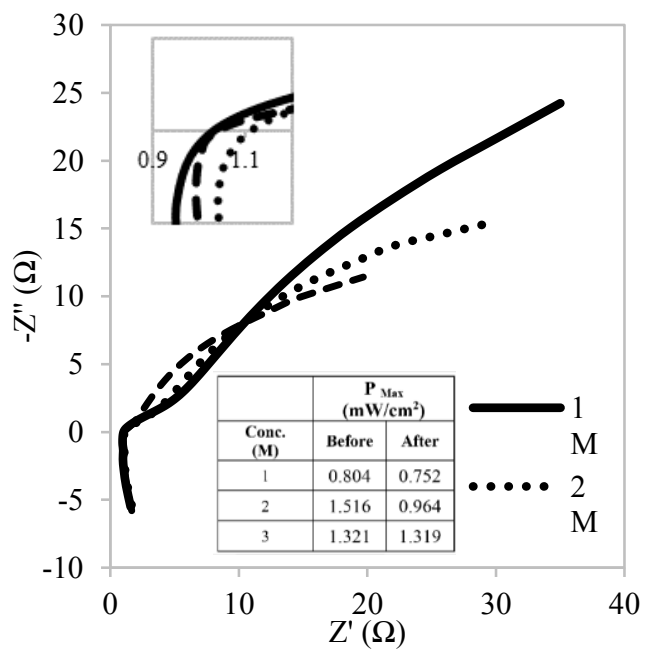

Fig. 9. Nyquist plot of the passive dual-cell DEFC operated at a cell voltage of $1.0 \mathrm{~V}$ and different ethanol concentrations operated after a steady voltage discharging measurement.

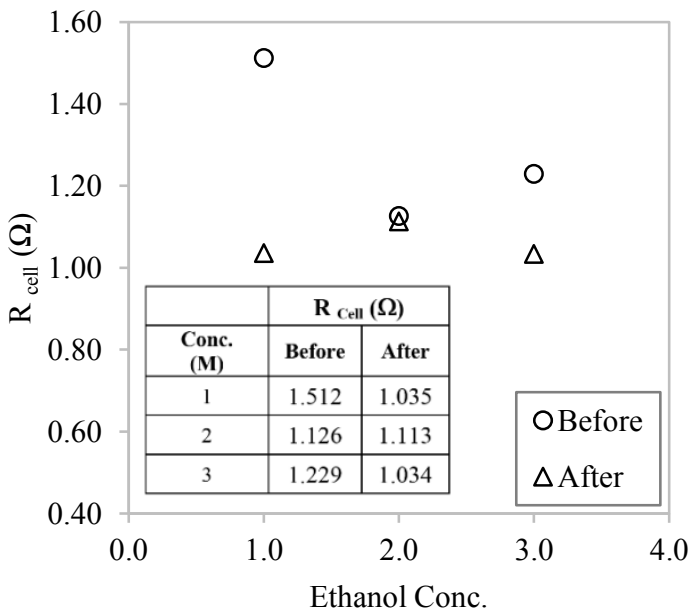

Fig. 10. Effect of ethanol concentration on the cell resistance $\left(\mathrm{R}_{\mathrm{Cell}}\right)$ at different periods: before and after a steady voltage discharging measurement.
Finally, open circuit voltage $(\mathrm{OCV})$ was related to ethanol crossover behavior. The ethanol crossover effect could result in a more negative effect on the OCV as distinguished from Fig. 11. Considering only the period before a steady voltage discharging measurement, the result showed that the OCV got the lowest when the cell was operated with the ethanol concentration of $3 \mathrm{M}$. It can be distinguished that the OCV was decreased with an increase of ethanol concentration due to the ethanol crossover increment. In addition, it appeared that the OCV after a steady voltage discharging measurement was almost the same comparing to that before one. The OCVs after a steady voltage discharging measurement slightly decreased due to the swelling of the membrane operated in aqueous solution in long period of time.

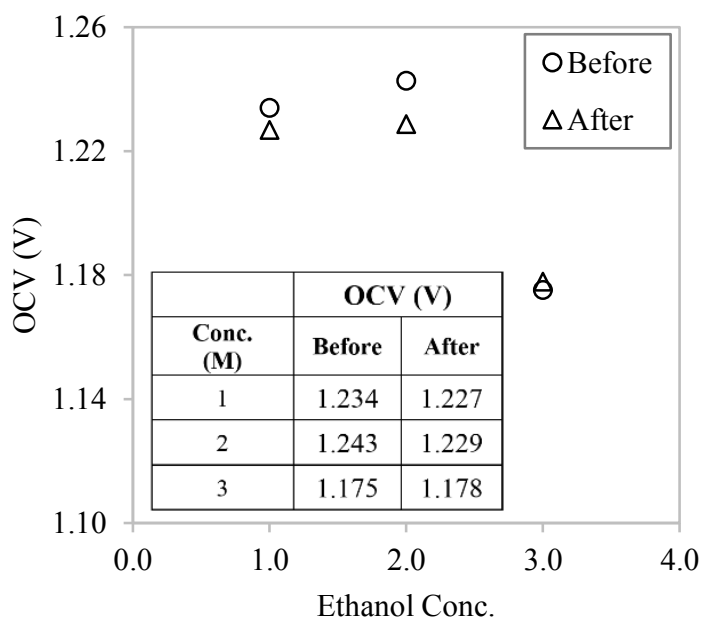

Fig. 11. Effect of ethanol concentration on the OCV at different periods: before and after a steady voltage discharging measurement pressure.

\section{Conclusion}

A dual-cell passive direct ethanol fuel cell (DEFC) stack with single ethanol tank was successfully designed to increase cell voltage. The cell performance and stability tests were conducted. It was found that, before a steady voltage discharging measurement, the highest maximum power density was $1.516 \mathrm{~mW} \cdot \mathrm{cm}^{-2}$ at an ethanol concentration of $2 \mathrm{M}$. Further increasing the ethanol concentration to above $2 \mathrm{M}$ yielded a lower maximum power. It is obvious that there is an optimal ethanol concentration to obtain high cell performance.

After the steady voltage discharging measurement, the maximum power density was also higher by feeding a higher ethanol concentration. The lowest maximum power density was at an ethanol concentration of $1 \mathrm{M}$, while the highest maximum power density was 1.319 $\mathrm{mW} \cdot \mathrm{cm}^{-2}$ at an ethanol concentration of $3 \mathrm{M}$. This circumstance is different from the period before a steady voltage discharging measurement. The reason is that, at the current density over 8,000 second, the cell operated with ethanol concentration of $2 \mathrm{M}$ evidently produced current density higher than that of $3 \mathrm{M}$ for a long time period. It may be mainly attributed to the immediate

\footnotetext{
* Corresponding author: panuwat.e@sciee.kmutnb.ac.th
} 
species poisoning the anode active layer leading to a lower cell performance.

It can be concluded from OCV that the high ethanol concentration used at $3 \mathrm{M}$ related to high ethanol diffusion through the membrane leading to high ethanol crossover and then lower cell performance. Moreover, EIS results showed that, after a steady voltage discharging measurement, the cell resistance of cell operated with ethanol concentration of $2 \mathrm{M}$ is the same. It was expected that the mass transfer of fuel and reactant entirely reaches to equilibrium in both chemical and physical phenomenon.

In summary, a dual-cell passive direct ethanol fuel cell (DEFC) stack is suggested to operate at the optimum ethanol concentration of $2 \mathrm{M}$. However, the degradation of cell performance could occur with a long-term constant voltage discharge. It is necessary to further improve the cell stability for practical application.

\section{References}

1. X. Li, A. Faghri, J. Power Sources. 226, 223 (2013)

2. B.C. Ong, S.K. Kamarudin, S. Basri, Int J Hydrog. Energy. 42, 10142 (2017)

3. M.Z.F. Kamaruddin, S.K. Kamarudin, W.R.W. Daud, M.S. Masdar, Renew Sust Energ Rev. 24, 557 (2013)

4. M.Z.F. Kamarudin, S.K. Kamarudin, M.S. Masdar, W.R.W. Daud, Int. J. Hydrog. Energy. 38, 9438 (2013)
5. J.P. Pereira, D.S. Falcao, V.B. Oliveira, A.M.F.R. Pinto, J. Power Sources. 256, 15 (2014)

6. Y.C. Park, D.H. Kim, S. Lim, S.K. Kim, D.H. Peck, D.H. Jung, Int. J. Hydrog. Energy, 37, 4717 (2012)

7. A.D.S. Gomes, J.C.D. Filho, Int. J. Hydrog. Energy. 37, 6246 (2012)

8. M.C. Figueiredo, O. Sorsa, R.M. Aran-Ais, N. Doan, J.M. Feliu, T. Kallio, J Catal 329, 69 (2015)

9. P. Ekdharmasuit, A. Therdthianwong, S. Therdthianwong, Fuel. 113, 69 (2013)

10. P. Ekdharmasuit, A. Therdthianwong, S. Therdthianwong, Int J Hydrog Energy. 39, 1775 (2014)

11. Z. Guo, A. Faghri, Int Commun Heat Mass. 35, 225 (2008)

12. L. Wang, M. He, Y. Hu, Y. Zhang, X. Liu, G. Wang, Energy. 82, 229 (2015)

13. M.S. Masdar, Dedikarni, A.M. Zainoodin, M.I. Rosli, S.K. Kamarudin, W.R.W. Daud, Int. J. Hydrog. Energy. 42, 9230 (2017)

14. J.P. Pereira, D.S. Falcao, V.B. Oliveira, A.M.F.R. Pinto, J Power Sources. 256, 14 (2014)

15. V.B. Oliveira, J.P. Pereira, A.M.F.R. Pinto, Energy. 133, 652 (2017)

16. Y.S. Li, T.S. Zhao, Int J Hydrog Energy. 41, 20336 (2016) 